\title{
Physiological Responses of Spring Wheat to 5-Aminolevulinic Acid under Water Stress Applied at Seedling Stage
}

\author{
A. Ostrowska*, J. Biesaga-Kościelniak, M.T. Grzesiak and T. Hura \\ Polish Academy of Sciences, The Franciszek Górski Institute of Plant Physiology \\ Niezapominajek 21, 30-239 Kraków, Poland
}

(Received 23 May 2018; Accepted 7 September 2018; Communicated by R.K. Behl)

\begin{abstract}
5-Aminolevulinic acid relieves the effects of environmental stresses in plants. Therefore, the aim of our study was to evaluate the effects of 5-aminolevulinic acid (5-ALA) on the activity of the photosynthetic apparatus in spring wheat. Other analyzed parameters involved plant height, relative turgidity, membrane status, and chlorophyll level. The plant material consisted of three genotypes of spring wheat $(\mathrm{J} \times \mathrm{Z}, \mathrm{R} \times \mathrm{K}, \mathrm{K} \times \mathrm{M})$, subjected to mild and severe drought in the early phase of vegetative development.

5-ALA showed a positive effect on the activity of the photosynthetic apparatus under water stress. The relieving action of 5-ALA on PSII was the most evident in $\mathrm{J} \times \mathrm{Z}$ genotype during severe soil drought. 5-ALA positively influenced the maximum photochemical efficiency of PSII $\left(\mathrm{F}_{\mathrm{v}} / \mathrm{F}_{\mathrm{m}}\right)$, the overall performance index of PSII photochemistry (PI) and the effective quantum field of PSII $\left(\varphi_{\mathrm{E} o}\right)$. In the same genotype, the investigated acid stimulated light energy absorption $\left(\mathrm{ABS} / \mathrm{CS}_{\mathrm{m}}\right)$, and enhanced the amount of excitation energy trapped in PSII reaction centers $\left(\mathrm{TR}_{\mathrm{o}} / \mathrm{CS}_{\mathrm{m}}\right)$ and the amount of energy used for electron transport $\left(\mathrm{ET}_{\mathrm{o}} / \mathrm{CS}_{\mathrm{m}}\right)$.

Moreover, 5-aminolevulinic acid showed its potential to overcome the adverse effects of water deficit on Triticum aestivum L. by increasing plant growth, relative turgidity, and chlorophyll content and reducing the degree of damage to cell membranes at the early phase of vegetative development.
\end{abstract}

Keywords: 5-aminolevulinic acid, chlorophyll fluorescence, drought stress, wheat

Abbreviations: 5-ALA - 5-aminolevulinic acid; $\mathrm{ABS} / \mathrm{CS}_{\mathrm{m}}$ - light energy absorption; $\mathrm{Chl}$ - chlorophyll; $\mathrm{CS}_{\mathrm{m}}$ - leaf cross-section; $\mathrm{DI}_{\mathrm{o}} / \mathrm{CS}_{\mathrm{m}}$ - energy amount dissipated from PSII; $\mathrm{EL}$ - electrolyte leakage; $\mathrm{ET}_{\mathrm{o}} / \mathrm{CS}_{\mathrm{m}}-$ amount of energy used for electron transport; $\mathrm{F}_{\mathrm{v}} / \mathrm{F}_{\mathrm{m}}-$ quantum yield of PSII; MWC - maximum water holding capacity; PI - overall performance index of PSII photochemistry; $\mathrm{RC} / \mathrm{CS}_{\mathrm{m}}$ - number of active reaction centers; $\mathrm{RT}$ - relative turgidity; $\mathrm{TR}_{\mathrm{o}} / \mathrm{CS}_{\mathrm{m}}$ - amount of excitation energy trapped in PSII reaction centers; $\varphi_{\text {Eo }}-$ quantum yield of electron transport

\footnotetext{
*Corresponding author; E-mail: a.ostrowska@ifr-pan.edu.pl; Phone: 4812 4251833; Fax: 48124251844
} 


\section{Introduction}

5-Aminolevulinic acid (5-ALA) is an essential precursor of all porphyrin compounds, including chlorophyll and heme, and occurs in all plants and animals (von Wettstein et al. 1995). The effect of exogenous application of 5-ALA on plants depends primarily on its concentration in the applied solution. At large doses it serves as a biodegradable photodynamic herbicide in agricultural production (Rebeiz et al. 1990), while at low concentrations it stimulates plant growth and development (Xu et al. 2010). According to numerous reports, 5-ALA is capable of mitigating the effects of such environmental stresses as cold (Korkmaz and Korkmaz 2009), drought (Al-Khateeb 2006), soil salinity (Nishihara et al. 2003; Zhang et al. 2006), shading (Sun et al. 2009) or heavy metals (Ali et al. 2013).

It also affects the activity of antioxidant enzymes (Balestrasse et al. 2010; Naeem et al. 2011; Liu et al. 2016), water relations (Korkmaz et al. 2010), gas exchange (Akram et al. 2018), and chlorophyll content (Xu et al. 2010).

The use of 5-ALA may be particularly beneficial in spring cereals of shorter growing season than the winter cereals and hence lower harvest potential. In addition, spring cereals are highly sensitive to spring droughts that happen at early stages of their growth and development (seedlings, beginning of tillering) (Gietler et al. 2017). The short vegetation period of spring cereals is often insufficient for full plant recovery after drought. A common reason for incomplete recovery is permanent damage to the photosynthetic apparatus caused by leaf dehydration (Hura et al. 2015).

Therefore, the main aim of this research was to assess the impact of 5-ALA on the activity of the photosynthetic apparatus as measured by chlorophyll fluorescence parameters. We assumed that an exogenous application of this substance would protect PSII. We also evaluated plant height, relative turgidity, membrane status, and chlorophyll level. The plant material were three genotypes of spring wheat subjected to water stress in the early phase of vegetative development.

\section{Materials and Methods}

\section{Plant materials and plant growth conditions}

The experiment involved three genotypes of spring wheat (Triticum aestivum L.) crossbreeds of the following cultivars: Raweta $\times$ Katoda $(\mathrm{R} \times \mathrm{K})$, Jasna $\times$ Zebra $(\mathrm{J} \times \mathrm{Z})$ and Katoda $\times$ Monsun $(\mathrm{K} \times \mathrm{M})\left(\mathrm{F}_{3}\right)$. The experiment was carried out in a growth chamber. Plants were grown in $5 \mathrm{dm}^{3}$ pots (9 pots per genotype with 12 plants each), filled with a mixture of soil and sand $(1: 1, \mathrm{v} / \mathrm{v})$. Vegetation was held at a $15 \mathrm{~h}$ photoperiod, irradiance of $450 \mu \mathrm{mol}$ (photon) $\mathrm{m}^{-2} \mathrm{~s}^{-1}$ (provided by high pressure sodium lamps, 400 W; Philips SON-T AGRO, Belgium), temperature of $24 / 18^{\circ} \mathrm{C}$ (day/night), and $50 \%$ air humidity. The plants were irrigated with full-strength Hoagland's nutrient solution once a week. Soil moisture was controlled gravimetrically every day. During this period, soil humidity was measured additionally with HydroSense Soil Water Content Measurement System (Campbell Scientific, Inc., Australia) at different sites of the pot to check homogeneity of water content. 


\section{Drought conditions and 5-ALA treatment}

At up to the third leaf stage, soil water content was kept at $70-75 \%$ maximum water capacity (MWC) by adding an appropriate amount of water each day. Drought started by discontinuing watering, and reached about $30 \%$ of MWC after eight days. At that time, leaves of all stressed genotypes showed visual symptoms of turgor loss. This level of soil humidity was maintained for the next 10 days. The control plants grew at $75 \%$ of MWC. The third group comprised plants sprayed with 5-ALA (30 $\left.\mathrm{mg} \mathrm{dm}^{-3}\right)$ solution before watering cessation. Each plant was sprayed with ca. $1 \mathrm{ml}$ of the solution. Physiological measurements were performed after reaching 30\% MWC - on the first day of drought (mild drought), and after 10 days of drought stress (severe drought).

\section{Photochemical efficiency}

Measurements were done in the central part of the first fully expanded leaf using a Handy PEA (Hansatech Ltd., UK). They were taken after $30 \mathrm{~min}$ of leaf adaptation to darkness. The excitation irradiance was $3000 \mu \mathrm{mol}$ (quantum) $\mathrm{m}^{-2} \mathrm{~s}^{-1}$ (peak at $650 \mathrm{~nm}$ ). Changes in fluorescence were registered during irradiation between $10 \mu \mathrm{s}$ and $1 \mathrm{~s}$. During the initial $2 \mathrm{~ms}$, data were collected every $10 \mu \mathrm{s}$ with 12 bit resolution. After this period, the frequency of measurements dropped automatically. The collected data were analyzed with a JIP test, based on the theory of energy flow in PSII (Srivastava and Strasser 1977; Lazár 1999; Strasser et al. 2000; Appenroth et al. 2001). The following parameters were calculated per excited leaf cross-section $\left(\mathrm{CS}_{\mathrm{m}}\right)$ : $\mathrm{ABS} / \mathrm{CS}_{\mathrm{m}}$ (light energy absorption), $\mathrm{TR}_{\mathrm{o}} / \mathrm{CS}_{\mathrm{m}}$ (amount of excitation energy trapped in PSII reaction centers), $\mathrm{ET}_{\mathrm{o}} / \mathrm{CS}_{\mathrm{m}}$ (amount of energy used for electron transport), $\mathrm{DI}_{\mathrm{o}} / \mathrm{CS}_{\mathrm{m}}$ (energy amount dissipated from PSII) and $\mathrm{RC} / \mathrm{CS}_{\mathrm{m}}$ (number of active reaction centers). Moreover, $\mathrm{F}_{\mathrm{v}} / \mathrm{F}_{\mathrm{m}}$ (quantum yield of PSII), $\varphi_{\mathrm{Eo}}$ (effective quantum yield of electron transport flux from the primary quinone acceptor $\mathrm{Q}_{\mathrm{A}}$ to $\mathrm{Q}_{\mathrm{B}}$ ) and PI (overall performance index of PSII photochemistry) were determined. Measurements involved 20 replicates (one replicate means one plant for all measurements).

\section{Relative turgidity (RT)}

Measurements were performed on the first fully developed leaf from the top. RT was determined according to Barrs and Weatherley (1962) formula:

$$
\mathrm{RT}=[(\mathrm{FW}-\mathrm{DW}) /(\mathrm{TW}-\mathrm{DW})] \times 100 \%
$$

where FW represents fresh weight, DW dry weight and TW turgid weight. To measure TW, leaves were placed in darkness for $24 \mathrm{~h}$ in vials containing water to allow complete rehydration. For estimating DW, the leaves were dried at $80^{\circ} \mathrm{C}$ for $48 \mathrm{~h}$. The measurements were taken in six replicates. 


\section{Chlorophyll content}

Measurements were performed in the first fully developed leaf from the top with handheld chlorophyll meters SPAD-502 (Konica-Minolta, Japan). The SPAD values were converted into chlorophyll content using spectrophotometric method according to Arnon (1949) and Jaspars (1965). Briefly, the leaves were homogenized with 80\% (v/v) acetone, and the crude extract was centrifuged at $3000 \mathrm{~g}$ for $5 \mathrm{~min}$ at $4{ }^{\circ} \mathrm{C}$. Absorbance of the supernatant was measured spectrophotometrically at 450, 645 and $663 \mathrm{~nm}$ (microplate reader Synergy 2, Biotek Ins, USA). The measurements were taken in 20 replicates.

\section{Plant height analysis}

Biometric analysis of main shoot for each treatment included 20 replicates.

\section{Electrolyte leakage (EL)}

For each genotype, three $3 \mathrm{~cm}$ leaf fragments were excised from the first fully developed leaf from the top. The samples were washed twice in deionized water and immersed in $10 \mathrm{~cm}^{3}$ of deionized water. After $24 \mathrm{~h}\left(\mathrm{t}_{1}\right)$ of shaking at room temperature, samples were frozen at $-30{ }^{\circ} \mathrm{C}$ for $24 \mathrm{~h}$, then heated and shaken again $\left(24 \mathrm{~h}\right.$, room temperature, $\left.\mathrm{t}_{2}\right)$. EL was calculated as follows:

$$
\mathrm{EL}=\left(\mathrm{EL}_{1} / \mathrm{EL}_{2}\right) \times 100 \%,
$$

where $\mathrm{EL}_{1}$ and $\mathrm{EL}_{2}$ represent specific electrical conductance at $t_{1}$ and $t_{2}$, respectively. Measurements of electrical conductance were performed using a microcomputer conductivity meter CC-317 (Elmetron, Poland). The measurements were taken in six replicates.

\section{Statistical analysis}

Duncan's multiple range test at $\mathrm{p}=0.05$ was performed in order to determine the significance of differences between treatments for a single genotype and day of drought. All data were analyzed using Statistica 10.0 software (Statsoft Inc., USA).

\section{Results}

\section{Photochemical activity}

The mitigating effect of 5-ALA on PSII was most evident in $\mathrm{J} \times \mathrm{Z}$ genotype during severe soil drought (Table 1). 5-ALA positively influenced the maximum photochemical efficiency of PSII $\left(\mathrm{F}_{\mathrm{v}} / \mathrm{F}_{\mathrm{m}}\right)$, the overall performance index of PSII photochemistry $(\mathrm{PI})$ and the effective quantum field of PSII $\left(\varphi_{\mathrm{Eo}}\right)$. In this genotype, 5-ALA stimulated light energy 


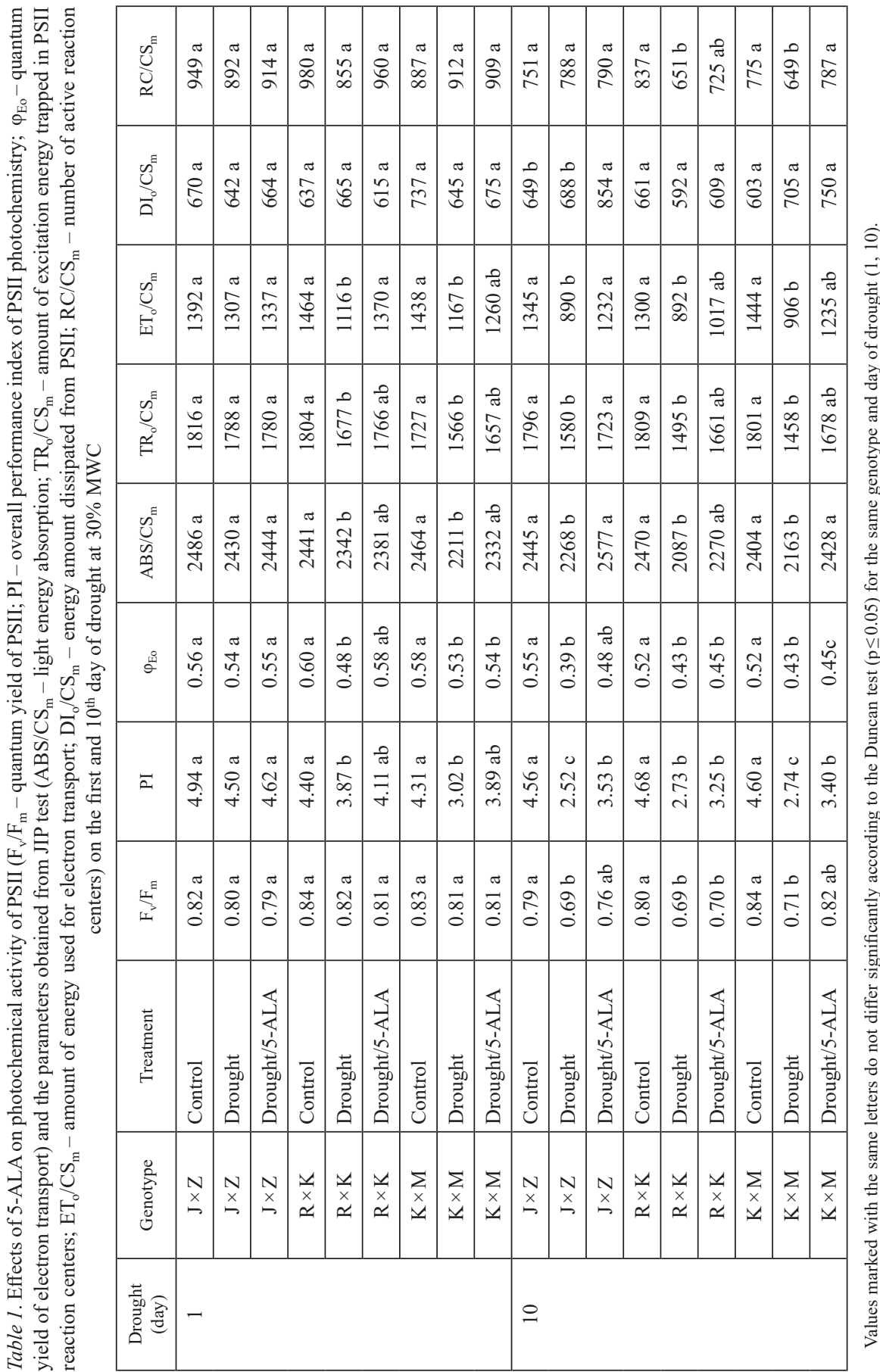


absorption $\left(\mathrm{ABS} / \mathrm{CS}_{\mathrm{m}}\right)$, and enhanced the amount of excitation energy trapped in PSII reaction centers $\left(\mathrm{TR}_{\mathrm{o}} / \mathrm{CS}_{\mathrm{m}}\right)$ and the amount of energy used for electron transport $\left(\mathrm{ET}_{\mathrm{o}} / \mathrm{CS}_{\mathrm{m}}\right)$.

5-ALA treatment of $\mathrm{K} \times \mathrm{M}$ genotype under severe drought revealed its positive effects on energy flow in PSII, RC/CS $, \mathrm{F}_{\mathrm{v}} / \mathrm{F}_{\mathrm{m}}, \mathrm{PI}$ and $\varphi_{\mathrm{Eo}}$. The effects of 5-ALA on the activity of the photosynthetic apparatus were the least visible in $\mathrm{R} \times \mathrm{K}$ genotype.

\section{Relative turgidity (RT)}

On the first day of drought at 30\% MWC, all genotypes showed about $14 \%$ decrease in RT (Table 2), as compared with optimally watered plants. Under the same conditions, treating $\mathrm{J} \times \mathrm{Z}$ and $\mathrm{K} \times \mathrm{M}$ with 5-ALA prevented a drop in leaf hydration. This beneficial influence of 5-ALA persisted after the next 10 days of drought.

Table 2. Effects of 5-ALA on the relative turgidity (RT), chlorophyll content (Chl.), plant height and electrolyte leakage (EL) on the first and $10^{\text {th }}$ day of drought at $30 \% \mathrm{MWC}$

\begin{tabular}{|c|c|c|c|c|c|c|}
\hline $\begin{array}{l}\text { Drought } \\
\text { [day] }\end{array}$ & Genotype & Treatment & $\begin{array}{l}\text { RT } \\
(\%)\end{array}$ & $\begin{array}{c}\text { Chl. } \\
\left(\mathrm{mg} \mathrm{g}^{-1} \text { D.W.) }\right.\end{array}$ & $\begin{array}{l}\text { Plant height } \\
(\mathrm{cm})\end{array}$ & $\begin{array}{l}\mathrm{EL} \\
(\%)\end{array}$ \\
\hline \multirow[t]{9}{*}{1} & $\mathrm{~J} \times \mathrm{Z}$ & Control & $95.30 \mathrm{a}$ & $30.84 \mathrm{a}$ & $16.0 \mathrm{a}$ & $4.34 \mathrm{~b}$ \\
\hline & $\mathrm{J} \times \mathrm{Z}$ & Drought & $84.55 \mathrm{~b}$ & $31.54 \mathrm{a}$ & $14.8 \mathrm{a}$ & $10.17 \mathrm{a}$ \\
\hline & $\mathrm{J} \times \mathrm{Z}$ & Drought/5-ALA & $91.30 \mathrm{a}$ & $32.06 \mathrm{a}$ & $14.6 \mathrm{a}$ & $7.70 \mathrm{ab}$ \\
\hline & $\mathrm{R} \times \mathrm{K}$ & Control & $94.61 \mathrm{a}$ & $32.61 \mathrm{a}$ & $17.7 \mathrm{a}$ & $4.14 \mathrm{~b}$ \\
\hline & $\mathrm{R} \times \mathrm{K}$ & Drought & $83.95 \mathrm{~b}$ & $28.51 \mathrm{~b}$ & $16.1 \mathrm{a}$ & $8.99 \mathrm{a}$ \\
\hline & $\mathrm{R} \times \mathrm{K}$ & Drought/5-ALA & $84.87 \mathrm{~b}$ & $30.94 \mathrm{ab}$ & $16.8 \mathrm{a}$ & $7.05 \mathrm{ab}$ \\
\hline & $\mathrm{K} \times \mathrm{M}$ & Control & $95.32 \mathrm{a}$ & $32.61 \mathrm{a}$ & $15.7 \mathrm{a}$ & $4.26 \mathrm{c}$ \\
\hline & $\mathrm{K} \times \mathrm{M}$ & Drought & $78.16 \mathrm{c}$ & $28.89 \mathrm{~b}$ & $13.9 \mathrm{a}$ & $9.76 \mathrm{a}$ \\
\hline & $\mathrm{K} \times \mathrm{M}$ & Drought/5-ALA & $86.32 \mathrm{~b}$ & $32.93 \mathrm{a}$ & $13.8 \mathrm{a}$ & $6.44 \mathrm{~b}$ \\
\hline \multirow[t]{9}{*}{10} & $\mathrm{~J} \times \mathrm{Z}$ & Control & $93.03 \mathrm{a}$ & $34.31 \mathrm{a}$ & $24.5 \mathrm{a}$ & $5.62 \mathrm{c}$ \\
\hline & $\mathrm{J} \times \mathrm{Z}$ & Drought & $61.20 \mathrm{c}$ & $23.86 \mathrm{~b}$ & $18.5 \mathrm{~b}$ & $14.30 \mathrm{a}$ \\
\hline & $\mathrm{J} \times \mathrm{Z}$ & Drought/5-ALA & $76.85 \mathrm{~b}$ & $24.97 \mathrm{~b}$ & $20.3 \mathrm{ab}$ & $11.47 \mathrm{~b}$ \\
\hline & $\mathrm{R} \times \mathrm{K}$ & Control & $92.41 \mathrm{a}$ & $30.65 \mathrm{a}$ & $25.9 \mathrm{a}$ & $5.94 \mathrm{c}$ \\
\hline & $\mathrm{R} \times \mathrm{K}$ & Drought & $75.70 \mathrm{~b}$ & $25.61 \mathrm{~b}$ & $19.2 \mathrm{~b}$ & $16.90 \mathrm{a}$ \\
\hline & $\mathrm{R} \times \mathrm{K}$ & Drought/5-ALA & $80.11 \mathrm{~b}$ & $28.15 \mathrm{c}$ & $22.2 \mathrm{ab}$ & $13.20 \mathrm{~b}$ \\
\hline & $\mathrm{K} \times \mathrm{M}$ & Control & $94.91 \mathrm{a}$ & $35.40 \mathrm{a}$ & $22.2 \mathrm{a}$ & $6.11 \mathrm{c}$ \\
\hline & $\mathrm{K} \times \mathrm{M}$ & Drought & $64.66 \mathrm{c}$ & $24.35 \mathrm{c}$ & $16.9 \mathrm{c}$ & $19.53 \mathrm{a}$ \\
\hline & $\mathrm{K} \times \mathrm{M}$ & Drought/5-ALA & $75.25 \mathrm{~b}$ & $29.02 \mathrm{~b}$ & $18.5 \mathrm{~b}$ & $13.56 \mathrm{~b}$ \\
\hline
\end{tabular}

Values marked with the same letters do not differ significantly according to the Duncan test $(p \leq 0.05)$ for the same genotype and day of drought $(1,10)$. 


\section{Chlorophyll content}

Both mild and severe drought reduced plant greenness (Table 2). $\mathrm{R} \times \mathrm{K}$ and $\mathrm{K} \times \mathrm{M}$ genotypes responded to mild drought (one day of drought at 30\% MWC) with a decrease in their greenness index. Spraying with 5-ALA eliminated this adverse symptoms - partly in $\mathrm{R} \times \mathrm{K}$ and completely in $\mathrm{K} \times \mathrm{M}$. After 10 days of severe drought all genotypes responded with lowered greenness index. Compared with drought controls, 5-ALA prevented a drop in chlorophyll content in $\mathrm{R} \times \mathrm{K}$ and $\mathrm{K} \times \mathrm{M}$ genotypes by $10 \%$ and $19 \%$, respectively.

\section{Plant height}

The plants showed no differences in height after eight days of not watering that is on the first day of drought at 30\% MWC (Table 2). Growth inhibition in all investigated genotypes manifested itself after 10 days of drought but the plants treated with 5-ALA were on average $12 \%$ higher than those exposed to drought only.

\section{Electrolyte leakage (EL)}

Application of 5-ALA mitigated adverse effects of leaf dehydration on the integrity of cytoplasmic membranes in both drought treatments and in all genotypes (Table 2).

\section{Discussion}

Our study confirmed the mitigating effect of 5-ALA on the activity of the photosynthetic apparatus at seedling stage. This was particularly noticeable for $\mathrm{J} \times \mathrm{Z}$ genotype (Table 1 ). We also showed the usefulness of chlorophyll fluorescence parameters in evaluating differences in individual genotype response to 5-ALA.

Van der Tol et al. (2009) claimed that chlorophyll fluorescence parameters facilitate assessment of relationships between photochemical reactions of photosynthetic light phase and efficiency of biochemical reactions during the dark phase. Changes in the performance of the photosynthetic apparatus induced by environmental stresses translate into disturbances of photosynthesis, which is often manifested by increased chlorophyll fluorescence (Lichtenthaler and Rinderle 1988).

Research published so far focused on the effects of 5-ALA on the intensity of photosynthesis (Xu et al. 2010; Naeem et al. 2011; Ali et al. 2013; Ahmad et al. 2017), and reports on its effects on photosynthetic apparatus activity are rare. Sun et al. (2009) demonstrated a stimulation of effective quantum yield of electron transport flux from the primary quinone acceptor $\mathrm{Q}_{\mathrm{A}}$ to $\mathrm{Q}_{\mathrm{B}}$ by 5-ALA in watermelon growing in the shade. The team also showed that 5-ALA inhibited the closure of active reaction center, which was accelerated by shade. They observed no direct effects 5-ALA on the activity of the donor side of PSII reaction center and its considerable influence on the acceptor side of PSII reaction center (Sun et al. 2009). 
Our study revealed positive effects of 5-ALA on the chlorophyll fluorescence parameters that describe energy transport in PSII. They were visible in two genotypes of spring wheat $-\mathrm{R} \times \mathrm{K}$ and $\mathrm{K} \times \mathrm{M}$. Other experiments investigating 5-ALA role in energy flow in photosystems yielded similar results (Ali et al. 2013; Liu et al. 2016). The most recent studies confirmed the influence of 5-ALA on quantum yield of PSII $\left(\mathrm{F}_{\mathrm{v}} / \mathrm{F}_{\mathrm{m}}\right)$ (Akram et al. 2012; Wang et al. 2018). Wang et al. (2018) showed also that 5-ALA affected transcript levels of PsbA and PsbD related to the expression of genes encoding D1 and D2 - crucial proteins of the photosystem II.

5-ALA applied during mild drought altered the content of chlorophyll, RT and EL, and under severe drought it also affected plant height (Table 2). The same effects of 5-ALA on plant biomass, water relations, electrolyte leakage and chlorophyll content were observed in Leymus chinensis exposed to drought stress (Liu et al. 2016). Other reports demonstrated protective activity of 5-ALA towards cytoplasmic membranes of pakchoi (Memon et al. 2009), rape (Naeem et al. 2011) and cauliflower (Ahmad et al. 2017). The protection offered by 5-ALA probably consists in the limitation of lipid peroxidation (Ahmad et al. 2017; Akram et al. 2018). Ali et al. (2013) showed that 5-ALA significantly improved the structure of leaf mesophyll cells grown in the presence of cadmium.

5-ALA is also a precursor of chlorophyll, and indeed we noticed a rise of chlorophyll content in our study. Akram and Ashraf (2013) demonstrated that 5-ALA treatment as a foliar spray might considerably improve chlorophyll formation at early growth stages. Other studies (Kosar et al. 2015; Ahmad et al. 2017; Akram et al. 2018) also confirmed the role of 5-ALA in controlling the content of chlorophyll $a$ and $b$.

Furthermore, numerous experimental reports corroborated 5-ALA impact on water management and plant growth (Al-Thabet 2006; Korkmaz et al. 2010; Naeem et al. 2011; Ali et al. 2013; Gill et al. 2015; Liu et al. 2016; Akram et al. 2018).

In conclusion, 5-ALA has a great potential in agriculture as a natural and environmentfriendly substance reducing the devastating impact of drought on plants. The outcomes of our study suggest that 5-ALA, at the early phase of vegetative development, is capable of overcoming the adverse effects of water deficit on Triticum aestivum L. by increasing plant growth, relative turgidity, and chlorophyll content and reducing the degree of damage to cell membranes. We also conclude that foliar application of 5-ALA alleviates drought stress in wheat seedlings by increasing photochemical activity of PSII and by improving the energy flow in PSII.

\section{References}

Ahmad, R., Ali, S., Hannan, F., Rizwan, M., Iqbal, M., Hassan, Z., Akram, N.A., Maqbool, S., Abbas, F. 2017. Promotive role of 5-aminolevulinic acid on chromium-induced morphological, photosynthetic, and oxidative changes in cauliflower (Brassica oleracea botrytis L.). Environ. Sci. Pollut. Res. 24:8814-8824.

Akram, N.A., Ashraf, M., Al-Qurainy, F. 2012. Aminolevulinic acid-induced changes in some key physiological attributes and activities of antioxidant enzymes in sunflower (Helianthus annuus L.) plants under saline regimes. Sci. Hortic. 142:143-148.

Akram, N.A., Ashraf, M. 2013. Regulation in plant stress tolerance by a potential plant growth regulator, 5-aminolevulinic acid. J. Plant Growth Regul. 32:663-679. 
Akram, N.A., Iqbal, M., Muhammad, A., Ashraf, M., Al-Qurainy, F., Shafiq, S. 2018. Aminolevulinic acid and nitric oxide regulate oxidative defense and secondary metabolisms in canola (Brassica napus L.) under drought stress. Protoplasma 255:163-174.

Ali, B., Wang, B., Ali, S., Ghani, M.A., Hayat, M.T., Yang, C., Xu, L., Zhou, W.J. 2013. 5-Aminolevulinic acid ameliorates the growth, photosynthetic gas exchange capacity, and ultrastructural changes under cadmium stress in Brassica napus L. J. Plant Growth Regul. 32:604-614.

Al-Khateeb, S.A. 2006. Promotive effect of 5-aminolevulinic acid on growth, yield and gas exchange capacity of barley (Hordeum vulgare L.) grown under different irrigation regimes. J. King Saud Univ. Agric. Sci. 18:103-111.

Al-Thabet, S.S. 2006. Promotive effect of 5-aminolevulinic acid on growth and yield of wheat grown under dry conditions. J. Agron. 5:45-49.

Appenroth, K.J., Stöckel, J., Srivastava, A., Strasser, R.J. 2001. Multiple effects of chromate on the photosynthetic apparatus of Spirodela polyrhiza as probed by OJIP chlorophyll a fluorescence measurements. Environ. Pollut. 115:49-64.

Arnon, D.I. 1949. Copper enzymes in isolated chloroplasts polyphenol oxidase in Beta vulgaris. Plant. Physiol. 24:1-15.

Balestrasse, K.B., Tomaro, M.L., Batlle, A., Noriega, G.O. 2010. The role of 5-aminolevulinic acid in the response to cold stress in soybean plants. Phytochemistry 71:2038-2045.

Barrs, H.D., Weatherley, P.E. 1962. A re-examination of the relative turgidity techniques for estimating water deficits in leaves. Aust. J. Biol. Sci. 15:413-428.

Gietler, M., Nykiel, M., Orzechowski, S., Fettke, J., Zagdańska, B. 2017. Protein carbonylation linked to wheat seedling tolerance to water deficiency. Environ. Exp. Bot. 137:84-95.

Gill, R.A., Ali, B., Islam, F., Farooq, M.A., Gill, M.B., Mwamba, T.M., Zhou, W. 2015. Physiological and molecular analyses of black and yellow seeded Brassica napus regulated by 5-aminolivulinic acid under chromium stress. Plant Physiol. Bioch. 94:130-143.

Hura, T., Hura, K., Ostrowska, A., Dziurka, K. 2015. Rapid plant rehydration initiates permanent and adverse changes in the photosynthetic apparatus of triticale. Plant Soil 97:127-145.

Jaspars, E.M.J. 1965. Pigmentation of tobacco crown-gall tissues cultured in vitro in dependence of the composition of the medium. Physiol. Plant 18:933-940.

Korkmaz, A., Korkmaz, Y. 2009. Promotion by 5-aminolevulenic acid of pepper seed germination and seedling emergence under low-temperature stress. Sci. Hortic. 119:98-102.

Korkmaz, A., Korkmaz, Y., Demirkiran, A.R. 2010. Enhancing chilling stress tolerance of pepper seedlings by exogenous application of 5-aminolevulinic acid. Environ. Exp. Bot. 67:495-501.

Kosar, F., Akrama, N.A., Ashraf, M. 2015. Exogenously-applied 5-aminolevulinic acid modulates some key physiological characteristics and antioxidative defense system in spring wheat (Triticum aestivum L.) seedlings under water stress. S. Afr. J. Bot. 96:71-77.

Lazár, D. 1999. Chlorophyll a fluorescence induction. Biochim. Biophys. Acta 1412:1-28.

Lichtenthaler, H.K., Rinderle, U. 1988. The role of chlorophyll fluorescence in the detection of stress conditions in plants. CRT Crit. Rev. Anal. Chem. 19:29-85.

Liu, M., Li, J., Niu, J., Wang, R., Song, J., Lv, J., Zong, X., Wang, S. 2016. Interaction of drought and 5-aminolevulinic acid on growth and drought resistance of Leymus chinensis seedlings. Acta Ecol. Sin. 36:180188.

Memon, S.A., Hou, X., Wang, L., Li, Y. 2009. Promotive effect of 5-aminolevulinic acid on chlorophyll, antioxidative enzymes and photosynthesis of Pakchoi (Brassica campestris ssp. Chinensis var. communis Tsen et Lee). Acta Physiol. Plant. 31:51-57.

Naeem, M.S., Rasheed, M., Liu, D., Jin, Z.L., Ming, D.F., Yoneyama, K., Takeuchi, Y., Zhou, W.J. 2011. 5-Aminolevulinic acid ameliorates salinity-induced metabolic, water-related and biochemical changes in Brassica napus L. Acta Physiol. Plant. 33:517-528.

Nishihara, E., Kondo, K., Parvez, M.M., Takahashi, K., Watanabe, K., Tanaka, K. 2003. Role of 5-aminolevulinic acid (ALA) on active oxygen-scavenging system in NaCl-treated spinach (Spinacia oleracea). J. Plant Physiol. 160:1085-1091. 
Rebeiz, C.A., Reddy, K.N., Nandihalli, U.B., Velu, J. 1990. Tetrapyrrole-dependent photodynamic herbicides. Photochem. Photobiol. 52:1099-1117.

Srivastava, A., Strasser, R.J. 1977. Constructive and destructive actions of light on the photosynthetic apparatus. J. Sci. Industrial Res. 56:133-148.

Strasser, R.J., Srivastava, A., Tsimilli-Michael, M. 2000. The fluorescence transient as a tool to characterize and screen photosynthetic samples. In: Yunus, M., Pathre, U., Mohanty, P. (eds), Probing photosynthesis: Mechanism, regulation and adaptation. Taylor and Francis, London, pp. 445-483.

Sun, Y.P., Zhang, Z.P., Wang, L.J. 2009. Promotion of 5-aminolevulinic acid treatment on leaf photosynthesis is related with increase of antioxidant enzyme activity in watermelon seedlings under shade condition. Photosynthetica 47:347-354.

Van Der Tol, C., Verhoef, W., Rosema, A. 2009. A model for chlorophyll fluorescence and photosynthesis at leaf scale. Agric. For. Meteorol. 149:96-105.

Von Wettstein, D., Gough, S., Kananagara, C.G. 1995. Chlorophyll biosynthesis. Plant Cell 7:1039-1105.

Wang, Y., Wei, S., Wang, J., Su, X., Suo, B., Qin, F., Zhao, H. 2018. Exogenous application of 5-aminolevulinic acid on wheat seedlings under drought stress enhances the transcription of $p s b A$ and $p s b D$ genes and improves photosynthesis. Braz. J. Bot. (doi:10.1007/s40415-018-0455-y).

Xu, F., Zhu, J., Cheng, S., Zhang, W., Wang, Y. 2010. Effect of 5-aminolevulinic acid on photosynthesis, yield, nutrition and medicinal values of kudzu (Pueraria phaseoloides). Trop. Grasslands 44:260-265.

Zhang, Z.J., Li, H.Z., Zhou, W.J., Takeuchi, Y., Yoneyama, K. 2006. Effect of 5-aminolevulinic acid on development and salt tolerance of potato (Solanum tuberosum L.) microtubers in vitro. Plant Growth Regul. 49:27-34. 